\title{
Qualidade de Vida Familiar: uma revisão integrativa sobre famílias de pessoas com deficiências
}

\author{
Family quality of life: an integrative review on the family of people \\ with disabilities
}

Ana Célia Nunes (https://orcid.org/0000-0001-8314-7486) ${ }^{1}$

Erika Aquino Marques Luiz (https://orcid.org/0000-0003-1712-2939) ${ }^{1}$

Patrícia Carla de Souza Della Barba (https://orcid.org/0000-0002-7893-8133) ${ }^{1}$
${ }^{1}$ Programa de PósGraduação em Terapia Ocupacional, Universidade Federal de São Carlos. Rodovia Washington Luis km 235. 13565-905 São Carlos SP Brasil. anacelia_nunes@ yahoo.com.br

\begin{abstract}
The objective of this integrative revision is to understand the Brazilian scientific production of the thematic focus on the family quality of life (FQoL) of people with disabilities, as well as the participating population, referential theory, and instruments used in the studies. The data survey was done in the BVS, Scielo, and PubMed databases, and in the Capes' Periodic portal, whose inclusion criteria were articles published from 2007 to 2018, available fully online, in Portuguese or English. These articles portrayed the theme of life quality of families of people with disabilities and articles from research done in Brazilian contexts. The results showed that only three of the 19 selected articles to the study analyzed the theme of FQoL directly including the aspects related to the construct. They also pointed out that WHOQOL-Bref was the most used instrument to evaluate the FQoL ( $n=11)$, followed by semi structured interviews $(n=5)$ and that only $10,5 \%$, i.e., two articles used the appropriated definition of the FQoL. The research determined that the thematic research is still in the beginning stage in the scientific national production, large use of individual constructs of life quality, and sparse presence of specific measures instruments to measure FQoL.
\end{abstract}

Key words Quality of life, family, People with disabilities
Resumo O objetivo desta revisão integrativa foi conhecer a produção científica brasileira sobre a temática da qualidade de vida familiar (QdVF) de pessoas com deficiências, assim como a população participante, o referencial teórico e os instrumentos utilizados nos estudos. Foi realizado um levantamento nas bases de dados BVS, SciELO, PubMed, e no portal de Periódicos da Capes, cujos critérios de inclusão foram artigos publicados no período de 2007 a 2018, disponiveis na integra e online, publicado em português ou inglês e que retratassem a temática da QdVF de pessoas com deficiência e artigos oriundos de estudos realizados em contextos brasileiros. Os resultados apontaram que apenas 3 dos 19 artigos selecionados exploraram diretamente o tema da QdVF incluindo aspectos relacionados ao construto; também apontaram que o WHOQOL-Bref foi o instrumento mais utilizado para avaliar a qualidade de vida $(n=11)$, seguido por entrevistas semiestruturadas $(n=5)$ e que apenas $10,5 \%$, ou seja, dois artigos utilizaram a definição apropriada de QdVF. Constatou-se com o estudo uma incipiência da temática na produção científica nacional, o uso expressivo de construtos individuais de qualidade de vida e escassa presença de instrumentos de medidas específicos para mensurar QdVF.

Palavras-chave Qualidade de vida, Família, Pessoas com deficiência 


\section{Introdução}

Compreender a qualidade de vida de famílias traz consigo o desafio de pensar a família para além das demandas individuais de seus membros. Trata-se da concepção da família enquanto unidade, foco de atenção e intervenção; é a arte de substituir a visão limitada apenas às necessidades individuais pela compreensão também das necessidades coletivas, para assim ofertar ferramentas que possam ajudar toda família a experimentar a sensação positiva de bem-estar.

Qualidade de vida familiar (QdVF) tornou-se uma área de considerável interesse internacional com o avanço das práticas centradas na família e é uma extensão natural dos estudos desenvolvidos no âmbito da qualidade de vida individual de pessoas com deficiências ${ }^{1}$.

Com o avanço do interesse e o aumento de investigações cientificas sobre QdVF no início dos anos 2000, pesquisadores da área direcionaram sua atenção para o desenvolvimento de instrumentos de medidas de QdVF, inicialmente investigada por meio de estudos qualitativos, esses estudos permitiram dar os primeiros passos na definição do construto².

Duas linhas de investigação despertaram o interesse pela conceitualização da QdVF: 1) o reconhecimento crescente da capacidade adaptativa, pontos fortes e positivos das famílias com um membro com deficiências; e 2) a mudança da compreensão sobre a deficiência, que passou de uma visão de limitações e déficits exclusivos da pessoa com deficiência e sua família, para uma visão que considera as influências dos contextos, dos ambientes, recursos que estes oferecem e as necessidades de apoio que as famílias apresentam na condução da vida de todos os seus membros, inclusive o membro com deficiência ${ }^{3}$.

A partir de uma extensa revisão de estudos teóricos e empíricos sobre QdVF que Zuna et al. ${ }^{4}$ chegaram a uma definição de QdVF: uma percepção dinâmica de bem-estar da família, coletivamente e subjetivamente definidos e informados por seus membros, em que as necessidades de nivel individual e familiar interagem (p. 262).

Essa definição traz consigo a combinação entre elementos objetivos e subjetivos que servem de orientação para aferição do conceito de QdFV, e tem sido uma referência para elaboração de práticas com este fim, pois apresenta componentes subjetivos ligados as impressões e necessidades individuais dos membros da família, sem perder o foco da unidade familiar com suas características próprias que não podem ser descri- tas atendendo somente necessidades individuais. Trata-se de um conceito dinâmico, que muda ao longo do tempo de acordo com o crescimento e desenvolvimento da pessoa com deficiência e sua família ${ }^{2,5}$.

Zuna et al. ${ }^{4}$ realizaram uma revisão de literatura sobre QdVF nas deficiências, examinando os achados e relacionando-os aos componentes de uma possível teoria (definições, conceitos, variáveis e relações entre variáveis) para o tema, alinhada aos preceitos da psicologia positiva - a Teoria Unificada de Qualidade de Vida Familiar $^{2,4}$. Essa teoria apresenta componentes que se relacionam e influenciam direta ou indiretamente a QdVF, são eles: (a) fatores relativos à família como unidade; (b) fatores relacionados a cada membro da família; (c) fatores relativos à ação e, (d) elementos sistêmicos.

Em 2013, Caya Chiu et al. ${ }^{3}$ revisaram e atualizaram a Teoria Unificada de Qualidade de Vida Familiar, ampliando, redefinindo e estabelecendo novos fatores que influenciam a QdVF. As autoras incorporaram à teoria original elementos como os fatores referentes aos inputs; fatores relacionados com os resultados, e reescreveram os fatores relativos a ação nomeando-os como fatores de nível de apoio familiar e nível de apoio individual. Com a nova proposta de Caya Chiu et al. ${ }^{3}$ a Teoria Unificada de Qualidade de Vida Familiar define-se por seis fatores (Figura 1).

A representação gráfica da estrutura conceitual da Teoria Unificada de Qualidade de Vida familiar (Figura 1) se constitui em uma rede de círculos sobrepostos onde as variáveis do sistema interagem de forma complexa entre si para produzir resultados satisfatórios ou insatisfatórios de QdVF.

As definições das variáveis que compõem a estrutura conceitual revisada e atualizada da Teoria Unificada de Qualidade de Vida Familiar são apresentadas sucitamente no Quadro 1.

A ênfase do modelo é a QV de cada um dos membros da família e da família como um todo, trazendo consigo a filosofia da capacitação/ empoderamento em que o ponto alvo é alcançar a participação ativa da família, capacitando-a para que a própria família reconheça suas necessidades, identifique suas prioridades e elabore estratégias para alcançar suas metas.

Considera-se que uma família possui qualidade de vida quando seus membros lutam e conseguem o que querem, se sentem satisfeitos com o que alcançam, sentem-se capacitadas a viver a vida que desejam, têm suas necessidades atendidas e quando desfrutam conjuntamente de uma 


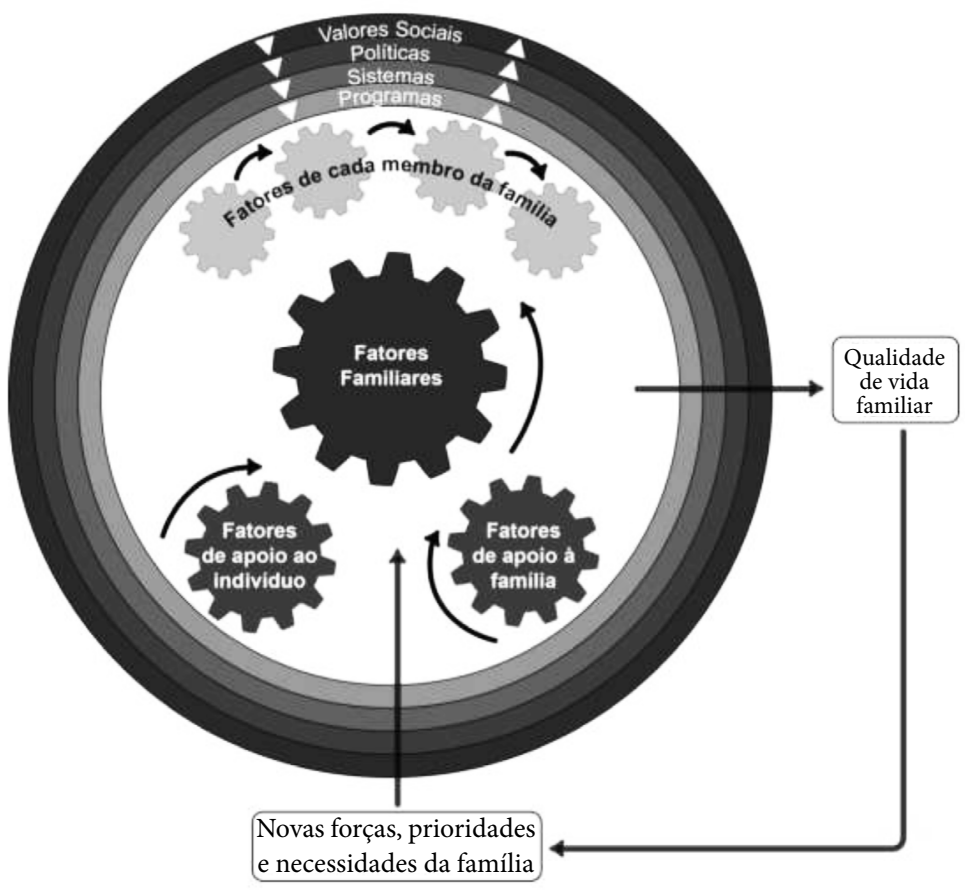

Figura 1. Estrutura conceitual revisada e atualizada da Teoria Unificada de Qualidade de Vida Familiar.

Fonte: Chiu C et al. ${ }^{3}$

Quadro 1. Variáveis de QdVF.

\begin{tabular}{|c|c|}
\hline \multicolumn{2}{|r|}{ Componentes de Qualidade de Vida Familiar } \\
\hline Variáveis & Definição \\
\hline $\begin{array}{l}\text { Fatores da unidade } \\
\text { familiar }\end{array}$ & $\begin{array}{l}\text { Refere-se à maneira pela qual uma família pode ser descrita enquanto unidade. Faz } \\
\text { referência aos aspectos inerentes às interações familiares e as relações contínuas } \\
\text { entre seus membros }\end{array}$ \\
\hline $\begin{array}{l}\text { Fatores individuais de } \\
\text { cada membro da família }\end{array}$ & $\begin{array}{l}\text { São características (dados demográficos, características e crenças individuais) de } \\
\text { cada indivíduo dentro de uma família. Dizem respeito às características básicas } \\
\text { como a idade, gênero e etnia, tipo e severidade das deficiências, nível educacional } \\
\text { dos pais e situação de emprego dos membros da família em idade produtiva }\end{array}$ \\
\hline $\begin{array}{l}\text { Fatores de Nível de } \\
\text { Suporte Familiar e Nível } \\
\text { de Suporte Individual }\end{array}$ & $\begin{array}{l}\text { São os apoios formais (serviços profissionais de reabilitação e educação especial, } \\
\text { por exemplo) e informais (família extensa, amigos, vizinhos etc.) que as famílias de } \\
\text { pessoas com deficiência recebem }\end{array}$ \\
\hline Fatores sistêmicos & $\begin{array}{l}\text { Representa o macroambiente dentro do qual as pessoas com deficiências e suas } \\
\text { famílias vivem suas vidas. Referem-se aos princípios constitucionais e éticos que } \\
\text { regem uma sociedade nos níveis federal, estadual e local, nos âmbitos da educação, } \\
\text { proteção social e cuidados em saúde }\end{array}$ \\
\hline $\begin{array}{l}\text { Fatores relacionados aos } \\
\text { resultados }\end{array}$ & $\begin{array}{l}\text { São os resultados produzidos pela interação entre fatores de cada membro e/ou os } \\
\text { fatores da unidade familiar individualmente, ou com os fatores de apoio individual } \\
\text { e/ou fatores de apoio da unidade familiar }\end{array}$ \\
\hline $\begin{array}{l}\text { Fatores relacionados aos } \\
\text { inputs }\end{array}$ & $\begin{array}{l}\text { São constituídos pelas novas forças, prioridades e necessidades da família que } \\
\text { entram novamente no sistema em um ciclo de retroalimentação }\end{array}$ \\
\hline
\end{tabular}

Fonte: Zuna et al. ${ }^{2,4} \mathrm{e}$ Chiu C et al. ${ }^{3}$ 
vida tranquila, planejando e conquistando metas que são significativas para todos $s^{6,7}$.

Diante do exposto acima, este estudo tem por objetivo conhecer a produção científica nacional sobre qualidade de vida familiar de pessoas com deficiências publicados entre os anos de 2007 a 2018, e ainda, descrever quem são os participantes dos estudos, o referencial teórico e os instrumentos utilizados para mensurar a QdVF, discutindo-os sob a luz da Teoria Unificada da Qualidade de Vida Familiar.

A partir dos objetivos supracitados, ressaltase que a hipótese que conduziu este estudo foi de que no Brasil as investigações sobre qualidade de vida de famílias de pessoas com deficiências focam-se em apenas um dos membros, especialmente o membro que exerce o papel de cuidador primário, e não no grupo familiar enquanto unidade.

Para fins desse estudo, identifica-se pessoa com deficiências a pessoa que tem impedimento de longo prazo de natureza física, mental, intelectual ou sensorial, o qual, em interação com uma ou mais barreiras, pode obstruir sua participação plena e efetiva na sociedade em igualdade de condições com as demais pessoas.

\section{Métodos}

Trata-se de uma revisão integrativa de literatura, ou seja, uma construção de uma análise ampla da literatura, contribuindo para discussões sobre métodos e resultados de pesquisas, assim como reflexões sobre a realização de futuros estudos ${ }^{9}$.

O estudo foi conduzido a partir das seguintes etapas: seleção da questão de pesquisa, formulação da hipótese; estabelecimento de critérios para inclusão e exclusão; seleção das bases de dados a serem consultadas; definição das palavras-chave e estratégias de buscas; definição das informações a serem extraídas dos estudos selecionados; identificação e seleção dos estudos; categorização e avaliação dos estudos incluídos; interpretação dos resultados; e apresentação da revisão/síntese do conhecimento?.

A questão norteadora desta pesquisa foi: "Como a literatura científica brasileira tem abordado a temática da qualidade de vida das famílias de pessoas com deficiência?".

Os critérios de inclusão definidos para a seleção dos artigos foram: os publicados de janeiro de 2007 a dezembro de 2018, disponíveis na íntegra e online, nos idiomas português ou inglês e indexados nas bases de dados BVS, SciELO, Pub-
Med, e no portal de Periódicos da Capes. Como critérios de inclusão foram definidos ainda: retratação da temática da qualidade de vida relacionada à família (qualquer membro da família ou cuidador familiar) de pessoas com deficiências e artigos oriundos de estudos realizados em contextos brasileiros.

Os critérios de exclusão foram: artigos em que a temática da qualidade de vida não fosse direcionada à família da pessoa com deficiências, ou seja, estudos de qualidade de vida direcionados exclusivamente à pessoa com deficiências. Foram excluídos artigos de revisão de literatura e artigos não realizados em contexto brasileiro.

Como estratégia de busca foram utilizados os descritores principais "Qualidade de Vida Familiar" em português, e "Family Quality of Life" em inglês. Também foram realizadas buscas cruzando os seguintes descritores, por meio de operação booleana: "Qualidade de Vida" AND "Família" AND "Deficiências" em português, e "Quality of Life" AND "Family" AND "Disability" em inglês.

Todos os achados foram comparados a fim de eliminar duplicidades existentes. Em seguida, foram realizadas leituras de títulos e resumos com os seguintes critérios: a) leitura do título com pelo menos um dos descritores cruzados em operação booleana ou descritor principal; b) leitura do resumo com satisfação dos seguintes critérios de inclusão: retratação da temática da qualidade de vida relacionada à família de pessoas com deficiência e artigos oriundos de estudos realizados em contextos brasileiros.

Por fim, fez-se a leitura completa dos artigos eleitos. Os artigos de revisão e aqueles que mesmo atendendo aos critérios de seleção (período da publicação e descritores) não abordavam a temática proposta foram excluídos.

\section{Resultados}

Foram encontrados 4.758 artigos a partir dos descritores, dos quais 4.730 foram descartados após aplicação dos filtros de pesquisa (ano de publicação, disponibilidade do artigo na íntegra e online, e idioma de publicação) e dos critérios de inclusão e exclusão, sendo selecionados 28 artigos para leitura completa.

Após a leitura completa, sete artigos foram descartados por não abordarem a temática da qualidade de vida relacionada à família de pessoas com deficiência ou por não ser artigo oriundo de estudos realizados em contexto brasileiro, e dois estudos foram eliminados por não especi- 
ficarem qual era a população-alvo dos cuidados fornecidos pelos cuidadores de sua amostra, restando 19 artigos para análise e discussão.

O Quadro 2 apresenta os principais dados encontrados nos artigos que compuseram a amostra (autores, objetivo, participantes do estudo, metodologia/ instrumento ou técnica para avaliar QdVF, referencial teórico ou tema de aprofundamento teórico/ definição de QV utilizada e principais resultados).

\section{Análise e discussão}

Embora nas últimas décadas tenha ocorrido um considerável aumento pelo interesse em investigações sobre qualidade de vida de pessoas com deficiências, despertando dessa forma o interesse pela qualidade de vida familiar e possibilitando uma crescente produção científica sobre esse tema no cenário internacional, os resultados encontrados nos estudos aqui revisados, conforme apresentado no Quadro 1, confirmam a hipótese que conduziu esta revisão de literatura à medida que 17 dos 19 artigos analisados tinham por

Quadro 2. Descrição dos principais dados encontrados nos artigos selecionados para a amostra final da revisão.

\begin{tabular}{|c|c|c|c|c|c|}
\hline Autores & Objetivo & $\begin{array}{c}\text { Participantes } \\
\text { do estudo }\end{array}$ & $\begin{array}{l}\text { Metodologia/ } \\
\text { instrumento } \\
\text { ou técnica para } \\
\text { avaliar QdVF }\end{array}$ & $\begin{array}{l}\text { Referencial Teórico } \\
\text { ou Tema de } \\
\text { aprofundamento } \\
\text { teórico/ Definição } \\
\text { de QV utilizada }\end{array}$ & Principais resultados \\
\hline $\begin{array}{l}\text { Costa et al. } \\
(2016)^{10}\end{array}$ & $\begin{array}{l}\text { Investigar a associação } \\
\text { entre os domínios } \\
\text { da qualidade de } \\
\text { vida relacionada à } \\
\text { saúde dos cuidadores } \\
\text { familiares e as } \\
\text { características } \\
\text { sociodemográficas } \\
\text { dos indivíduos com } \\
\text { sequelas de Acidente } \\
\text { Vascular Encefálico } \\
\text { (AVE) }\end{array}$ & $\begin{array}{l}136 \\
\text { cuidadores }\end{array}$ & $\begin{array}{l}\text { Quantitativa/ } \\
\text { Instrumento } \\
\text { Short-Form-36 } \\
\text { (SF-36) }\end{array}$ & $\begin{array}{l}\text { QV relacionada à } \\
\text { saúde / QV segundo } \\
\text { a OMS }\end{array}$ & $\begin{array}{l}\text { QV relacionada à saúde } \\
\text { dos cuidadores familiares } \\
\text { apresentou-se comprometida } \\
\text { em quase todos os domínios } \\
\text { avaliados. Diferenças de } \\
\text { QV ligadas a aspectos } \\
\text { sociodemográficos dos } \\
\text { indivíduos com sequela de } \\
\text { AVE (idade, estado civil e } \\
\text { escolaridade) }\end{array}$ \\
\hline $\begin{array}{l}\text { Jorge et al. } \\
(2015)^{11}\end{array}$ & $\begin{array}{l}\text { Adaptar culturalmente } \\
\text { a Escala de Qualidade } \\
\text { de Vida Familiar } \\
\text { (Family Quality of Life } \\
\text { Scale - FQOLS) para } \\
\text { a versão em Português } \\
\text { Brasileiro (PB), avaliar } \\
\text { a confiabilidade } \\
\text { do instrumento e a } \\
\text { qualidade de vida } \\
\text { familiar (QVF) das } \\
\text { famílias que possuem } \\
\text { filhos com deficiência } \\
\text { auditiva }\end{array}$ & 41 pais & $\begin{array}{l}\text { Quantitativo } \\
\text { / Escala de } \\
\text { Qualidade de } \\
\text { Vida Familiar } \\
\text { (FQOLS) }\end{array}$ & $\begin{array}{l}\text { Aspectos de QdVF } \\
\text { sem especificar uma } \\
\text { teoria/ Não há }\end{array}$ & $\begin{array}{l}\text { A escala FQOLS, mostrou- } \\
\text { se um instrumento de } \\
\text { fácil aplicação e com } \\
\text { confiabilidade satisfatória. As } \\
\text { famílias avaliadas apontaram } \\
\text { satisfação com sua QV } \\
\text { familiar. O instrumento } \\
\text { auxilia os profissionais } \\
\text { da saúde a compreender } \\
\text { melhor a dinâmica } \\
\text { familiar, as fragilidades e as } \\
\text { singularidades de cada família }\end{array}$ \\
\hline $\begin{array}{l}\text { Nascimento } \\
\text { et al. } \\
(2016)^{12}\end{array}$ & $\begin{array}{l}\text { Investigar a relação } \\
\text { da classificação } \\
\text { socioeconômica } \\
\text { e a percepção da } \\
\text { qualidade de vida de } \\
\text { pessoas que possuem } \\
\text { um familiar com } \\
\text { deficiência auditiva }\end{array}$ & 20 familiares & $\begin{array}{l}\text { Quantitativa/ } \\
\text { WHOQOL-Bref }\end{array}$ & $\begin{array}{l}\text { Família como } \\
\text { promotora de } \\
\text { desenvolvimento } \\
\text { infantil (influências } \\
\text { ecológicas no } \\
\text { desenvolvimento } \\
\text { infantil) / QV } \\
\text { segundo a OMS }\end{array}$ & $\begin{array}{l}\text { Relação diretamente } \\
\text { proporcional entre a } \\
\text { classificação socioeconômica } \\
\text { e a percepção da QV dos } \\
\text { familiares, em todos os } \\
\text { domínios avaliados na } \\
\text { pesquisa, exceto para o } \\
\text { domínio ambiental }\end{array}$ \\
\hline
\end{tabular}


Quadro 2. Descrição dos principais dados encontrados nos artigos selecionados para a amostra final da revisão.

\begin{tabular}{|c|c|c|c|c|c|}
\hline Autores & Objetivo & $\begin{array}{c}\text { Participantes } \\
\text { do estudo }\end{array}$ & $\begin{array}{l}\text { Metodologia/ } \\
\text { instrumento } \\
\text { ou técnica para } \\
\text { avaliar QdVF }\end{array}$ & $\begin{array}{c}\text { Referencial Teórico } \\
\text { ou Tema de } \\
\text { aprofundamento } \\
\text { teórico/ Definição } \\
\text { de QV utilizada }\end{array}$ & Principais resultados \\
\hline $\begin{array}{l}\text { Tomaz et al. } \\
(2017)^{13}\end{array}$ & $\begin{array}{l}\text { Investigar o impacto } \\
\text { da deficiência } \\
\text { intelectual moderada } \\
\text { na dinâmica e na } \\
\text { qualidade de vida } \\
\text { familiar }\end{array}$ & 15 mães & $\begin{array}{l}\text { Qualitativa/ } \\
\text { Entrevista } \\
\text { semiestruturada }\end{array}$ & $\begin{array}{l}\text { Modelo sistêmico } \\
\text { e Qualidade de } \\
\text { Vida familiar (sem } \\
\text { mencionar uma } \\
\text { teoria) / QdVF } \\
\text { segundo a definição } \\
\text { da Teoria Unificada } \\
\text { da QdVF }\end{array}$ & $\begin{array}{l}\text { Cuidado do filho deficiente } \\
\text { centrado na mãe; interferência } \\
\text { na qualidade da relação } \\
\text { conjugal; maior carga } \\
\text { de responsabilidade na } \\
\text { manutenção da harmonia } \\
\text { familiar para o papel } \\
\text { feminino; Intensa simbiose } \\
\text { entre mãe e filho com } \\
\text { deficiência e interferência na } \\
\text { relação com os demais } \\
\text { filho; As escolas, principal } \\
\text { instituição comunitária para } \\
\text { crianças e adolescentes, } \\
\text { foram consideradas } \\
\text { inadequadas, repercutindo } \\
\text { negativamente na QV } \\
\text { das famílias investigadas; } \\
\text { Dificuldades na obtenção de } \\
\text { informações e no acesso a } \\
\text { serviços de saúde e educação, } \\
\text { somadas à percepção de que } \\
\text { a qualidade dos cuidados } \\
\text { prestados é insatisfatória } \\
\text { representam grande } \\
\text { fonte de estresse familiar; } \\
\text { empobrecimento familiar } \\
\text { e dificuldades financeiras } \\
\text { como resultado do abandono } \\
\text { do mercado de trabalho } \\
\text { pelas mães, dificuldades } \\
\text { em coordenar as agendas e } \\
\text { os interesses dos diferentes } \\
\text { membros da família, foram } \\
\text { aspectos identificados como } \\
\text { complicadores do lazer } \\
\text { familiar }\end{array}$ \\
\hline $\begin{array}{l}\text { Ponte; } \\
\text { Fedosse } \\
(2016)^{14}\end{array}$ & $\begin{array}{l}\text { Correlacionar o } \\
\text { impacto da LEA na } \\
\text { atividade laboral de } \\
\text { sujeitos em idade } \\
\text { produtiva a suas QV, } \\
\text { bem como à de seus } \\
\text { familiares }\end{array}$ & $\begin{array}{l}48 \text { sujeitos } \\
\text { com LEA e } \\
27 \text { familiares }\end{array}$ & $\begin{array}{l}\text { Quali- } \\
\text { Quantitativa/ } \\
\text { WHOQOL-Bref }\end{array}$ & $\begin{array}{l}\text { Dados clínicos, } \\
\text { demográficos e } \\
\text { impacto da LEA na } \\
\text { vida dos sujeitos / } \\
\text { QV segundo a OMS }\end{array}$ & $\begin{array}{l}\text { Conclui que o surgimento de } \\
\text { uma LEA, de forma súbita, } \\
\text { causa sequelas incapacitantes: } \\
\text { desorganiza o sujeito e sua } \\
\text { família, afetando a sua QV em } \\
\text { todos os aspectos }\end{array}$ \\
\hline
\end{tabular}

continua

objetivo a análise da qualidade de vida de cuidadores principais ou a qualidade de vida de um dos familiares de pessoas com deficiências (pais ou irmãos). Além disso, dados como as caracte- rísticas dos instrumentos e o referencial teórico utilizados nos estudos, também corroboram com a confirmação da hipótese condutora da presente revisão. 
Quadro 2. Descrição dos principais dados encontrados nos artigos selecionados para a amostra final da revisão.

\begin{tabular}{|c|c|c|c|c|c|}
\hline Autores & Objetivo & $\begin{array}{c}\text { Participantes } \\
\text { do estudo }\end{array}$ & $\begin{array}{l}\text { Metodologia/ } \\
\text { instrumento } \\
\text { ou técnica para } \\
\text { avaliar QdVF }\end{array}$ & $\begin{array}{l}\text { Referencial Teórico } \\
\text { ou Tema de } \\
\text { aprofundamento } \\
\text { teórico/ Definição } \\
\text { de QV utilizada }\end{array}$ & Principais resultados \\
\hline $\begin{array}{l}\text { Braccialli et } \\
\text { al. }(2012)^{15}\end{array}$ & $\begin{array}{l}\text { Analisar e comparar a } \\
\text { qualidade de vida em } \\
\text { saúde de cuidadores } \\
\text { de pessoas com } \\
\text { necessidades especiais } \\
\text { em atendimento em } \\
\text { uma instituição de } \\
\text { reabilitação }\end{array}$ & 90 cuidadores & $\begin{array}{l}\text { Quantitativa/ } \\
\text { WHOQOL-Bref }\end{array}$ & $\begin{array}{l}\text { Saúde e Sobrecarga } \\
\text { do Cuidador/ QV } \\
\text { segundo a OMS }\end{array}$ & $\begin{array}{l}\text { A QV foi classificada como } \\
\text { boa e o domínio ambiental } \\
\text { recebeu a menor pontuação }\end{array}$ \\
\hline $\begin{array}{l}\text { Oliveira et } \\
\text { al. }(2008)^{16}\end{array}$ & $\begin{array}{l}\text { Compreender a } \\
\text { qualidade de vida do } \\
\text { cuidador de crianças } \\
\text { com paralisia cerebral }\end{array}$ & 08 mães & $\begin{array}{l}\text { Qualitativa/ } \\
\text { Entrevista } \\
\text { semiestruturada }\end{array}$ & $\begin{array}{l}\text { Qualidade de Vida } \\
\text { relacionada à Saúde/ } \\
\text { QV segundo a } \\
\text { OMS/ }\end{array}$ & $\begin{array}{l}\text { Dificuldades Enfrentadas } \\
\text { no transporte, recurso } \\
\text { financeiro, saúde, Vida } \\
\text { social (lazer), Projetos } \\
\text { de vida e Enfrentamento } \\
\text { (religiosidade); e, qualidade } \\
\text { de vida das cuidadoras } \\
\text { compreendida como } \\
\text { insatisfatória }\end{array}$ \\
\hline $\begin{array}{l}\text { Moretti et } \\
\text { al. }(2012)^{17}\end{array}$ & $\begin{array}{l}\text { Avaliar a qualidade de } \\
\text { vida dos cuidadores de } \\
\text { crianças com paralisia } \\
\text { cerebral atendidas } \\
\text { na Associação dos } \\
\text { Pais e Amigos dos } \\
\text { Excepcionais (APAE) } \\
\text { de Rio Branco-AC, } \\
\text { na Amazônia Sul } \\
\text { Ocidental, Brasil } \\
\end{array}$ & 12 cuidadores & $\begin{array}{l}\text { Qualitativa/ } \\
\text { Entrevista } \\
\text { semiestruturada }\end{array}$ & $\begin{array}{l}\text { QV relacionada } \\
\text { à saúde; Saúde } \\
\text { e sobrecarga do } \\
\text { cuidador/ QV } \\
\text { segundo a OMS }\end{array}$ & $\begin{array}{l}\text { A QV dos cuidadores } \\
\text { foi compreendida como } \\
\text { insatisfatória, principalmente } \\
\text { quando relacionada ao } \\
\text { domínio psicológico e nível } \\
\text { de independência }\end{array}$ \\
\hline $\begin{array}{l}\text { Favero- } \\
\text { Nunes; } \\
\text { Santos } \\
(2010)^{18}\end{array}$ & $\begin{array}{l}\text { Avaliar a prevalência } \\
\text { de disforia/sintomas } \\
\text { depressivos em } \\
\text { mães de crianças } \\
\text { com transtorno } \\
\text { autístico e identificar } \\
\text { possíveis relações } \\
\text { com qualidade de } \\
\text { vida e características } \\
\text { sociodemográficas }\end{array}$ & 20 mães & $\begin{array}{l}\text { Quantitativa/ } \\
\text { WHOQOL-Bref }\end{array}$ & $\begin{array}{l}\text { Dados clínicos e } \\
\text { sociodemográficos } \\
\text { de Indivíduos com } \\
\text { TID; Saúde mental } \\
\text { materna; QV } \\
\text { relacionada a saúde/ } \\
\text { QV segundo a OMS }\end{array}$ & $\begin{array}{l}\text { A maioria das participantes } \\
\text { avaliou positivamente sua } \\
\text { QV; mães com maior nível de } \\
\text { escolaridade se mostraram } \\
\text { menos vulneráveis aos } \\
\text { critérios para disforia/ } \\
\text { depressão e apresentaram } \\
\text { maiores escores nos domínios } \\
\text { psicológico, ambiental e físico } \\
\text { de QV }\end{array}$ \\
\hline $\begin{array}{l}\text { Reis et al. } \\
(2013)^{19}\end{array}$ & $\begin{array}{l}\text { Avaliar a QV O e } \\
\text { fatores associados de } \\
\text { cuidadores de idosos } \\
\text { com deficiência } \\
\text { funcional para } \\
\text { ajudar a planejar } \\
\text { e adotar medidas } \\
\text { multidisciplinares } \\
\text { para melhorar a } \\
\text { qualidade de vida dos } \\
\text { cuidadores }\end{array}$ & 40 cuidadores & $\begin{array}{l}\text { Quantitativa/ } \\
\text { WHOQOL-Bref }\end{array}$ & $\begin{array}{l}\text { Saúde e sobrecarga } \\
\text { do cuidador/ Não } \\
\text { há }\end{array}$ & $\begin{array}{l}\text { QV de cuidadores mais } \\
\text { comprometidas nos domínios } \\
\text { físicos e ambiental e menos } \\
\text { prejudicada no domínio } \\
\text { psicológico; alta prevalência } \\
\text { de problemas de saúde entre } \\
\text { os cuidadores e QV afetada } \\
\text { pela sobrecarga do cuidado }\end{array}$ \\
\hline
\end{tabular}


Quadro 2. Descrição dos principais dados encontrados nos artigos selecionados para a amostra final da revisão.

\begin{tabular}{|c|c|c|c|c|c|}
\hline Autores & Objetivo & $\begin{array}{c}\text { Participantes } \\
\text { do estudo }\end{array}$ & $\begin{array}{l}\text { Metodologia/ } \\
\text { instrumento } \\
\text { ou técnica para } \\
\text { avaliar QdVF }\end{array}$ & $\begin{array}{l}\text { Referencial Teórico } \\
\text { ou Tema de } \\
\text { aprofundamento } \\
\text { teórico/ Definição } \\
\text { de QV utilizada }\end{array}$ & Principais resultados \\
\hline $\begin{array}{l}\text { Silva; } \\
\text { Fedosse } \\
(2018)^{20}\end{array}$ & $\begin{array}{l}\text { Traçar o perfil } \\
\text { sociodemográfico e a } \\
\text { qualidade de vida de } \\
\text { cuidadores de pessoas } \\
\text { com deficiência } \\
\text { intelectual de uma } \\
\text { cidade de pequeno } \\
\text { porte do interior do } \\
\text { Rio Grande do Sul/ } \\
\text { Brasil }\end{array}$ & $\begin{array}{l}75 \\
\text { cuidadores; } \\
71 \text { familiares } \\
\text { e } 4 \\
\text { cuidadores } \\
\text { formais }\end{array}$ & $\begin{array}{l}\text { Quantitativa/ } \\
\text { WHOQOL-Bref }\end{array}$ & $\begin{array}{l}\text { Família enquanto } \\
\text { protetora/ saúde } \\
\text { e sobrecarga do } \\
\text { cuidador/ QdVF } \\
\text { de acordo com a } \\
\text { Teoria Unificada de } \\
\text { Qualidade de Vida } \\
\text { Familiar }\end{array}$ & $\begin{array}{l}\text { Verificou-se que as } \\
\text { pontuações médias mais } \\
\text { elevadas no domínio } \\
\text { social, seguido do físico, do } \\
\text { psicológico e, finalmente, } \\
\text { o domínio ambiental, } \\
\text { com poucas diferenças } \\
\text { entre homens e mulheres. } \\
\text { Vivencia de situaçoes } \\
\text { difíceis e mudanças de } \\
\text { ordem econômica, física e/ } \\
\text { ou emocional. Abdicação } \\
\text { de atividades prazerosas } \\
\text { para se dedicar ao cuidado; } \\
\text { isolamento social, redução } \\
\text { das relações interpessoais: } \\
\text { foco no ambiente domiciliar e } \\
\text { religioso }\end{array}$ \\
\hline $\begin{array}{l}\text { Bittencourt; } \\
\text { Hoehne } \\
(2009)^{21}\end{array}$ & $\begin{array}{l}\text { Avaliar a qualidade de } \\
\text { vida de pais de pessoas } \\
\text { surdas de um serviço } \\
\text { de reabilitação }\end{array}$ & $\begin{array}{l}15 \text { familiares } \\
\text { de pessoas } \\
\text { surdas }\end{array}$ & $\begin{array}{l}\text { Quantitativa/ } \\
\text { WHOQOL-Bref }\end{array}$ & $\begin{array}{l}\text { Impacto da surdez/ } \\
\text { QV em saúde e QV } \\
\text { segundo a OMS }\end{array}$ & $\begin{array}{l}80,0 \% \text { dos pais entrevistados } \\
\text { referiram ter "boa" ou "muito } \\
\text { boa" qualidade de vida; } \\
80,0 \% \text { dos entrevistados } \\
\text { referiram estar "satisfeitos" } \\
\text { ou "muito satisfeitos" com } \\
\text { sua saúde; menor percepção } \\
\text { de qualidade de vida nos } \\
\text { domínios de meio ambiente e } \\
\text { no domínio psicológico }\end{array}$ \\
\hline $\begin{array}{l}\text { Lima et al. } \\
(2014)^{22}\end{array}$ & $\begin{array}{l}\text { Descrever e comparar } \\
\text { a QV dos indivíduos } \\
\text { com AVE e de seus } \\
\text { cuidadores }\end{array}$ & $\begin{array}{l}210 \\
\text { participantes, } \\
\text { divididos } \\
\text { em } 4 \\
\text { grupos: AVE } \\
\text { com } \\
\text { cuidadores } \\
\text { (44); } \\
\text { AVE sem } \\
\text { cuidadores } \\
\text { (39); } \\
\text { cuidadores } \\
\text { (44) e grupo } \\
\text { controle (83) }\end{array}$ & $\begin{array}{l}\text { Quantitativa/ } \\
\text { WHOQOL-Bref }\end{array}$ & $\begin{array}{l}\text { Dados } \\
\text { sociodemográficos } \\
\text { do AVE/ QV } \\
\text { segundo a OMS }\end{array}$ & $\begin{array}{l}\text { Em todos os domínios para o } \\
\text { grupo de } \\
\text { indivíduos com AVE que } \\
\text { têm cuidadores e o grupo } \\
\text { de indivíduos com AVE } \\
\text { sem cuidadores os escores } \\
\text { médios foram menores que } \\
\text { os escores médios do grupo } \\
\text { dos cuidadores e o escore } \\
\text { médio deste menor do que } \\
\text { o do grupo de referência; } \\
\text { o domínio físico foi o mais } \\
\text { comprometido para o grupo } \\
\text { de AVE com cuidadores } \\
\text { e o menos afetado para o } \\
\text { grupo de cuidadores e grupo } \\
\text { controle }\end{array}$ \\
\hline
\end{tabular}

Notou-se, ainda com os resultados apresentados no Quadro 1, a predominância de estudos com abordagem quantitativa $(n=13)$ e artigos publicados em periódicos da área da saúde, com predominância de periódicos na área de Saúde Coletiva, Fonoaudiologia e Enfermagem. 
Quadro 2. Descrição dos principais dados encontrados nos artigos selecionados para a amostra final da revisão.

\begin{tabular}{|c|c|c|c|c|c|}
\hline Autores & Objetivo & $\begin{array}{c}\text { Participantes } \\
\text { do estudo }\end{array}$ & $\begin{array}{l}\text { Metodologia/ } \\
\text { instrumento } \\
\text { ou técnica para } \\
\text { avaliar QdVF }\end{array}$ & $\begin{array}{c}\text { Referencial Teórico } \\
\text { ou Tema de } \\
\text { aprofundamento } \\
\text { teórico/ Definição } \\
\text { de QV utilizada }\end{array}$ & Principais resultados \\
\hline $\begin{array}{l}\text { Oliveira; } \\
\text { Limongi } \\
(2011)^{23}\end{array}$ & $\begin{array}{l}\text { Avaliar a QV de pais / } \\
\text { cuidadores de crianças } \\
\text { e adolescentes com } \\
\text { Síndrome de Down } \\
\text { (SD) e a influência } \\
\text { de aspectos sócio- } \\
\text { demográficos nos } \\
\text { resultados obtidos }\end{array}$ & $\begin{array}{l}31 \text { pais/ } \\
\text { cuidadores }\end{array}$ & $\begin{array}{l}\text { Quantitativa/ } \\
\text { WHOQOL-Bref }\end{array}$ & $\begin{array}{l}\text { Qualidade de vida } \\
\text { relacionada á saúde; } \\
\text { dinâmica familiar } \\
\text { na SD. QV segundo } \\
\text { a OMS }\end{array}$ & $\begin{array}{l}\text { A maioria dos pais/ } \\
\text { cuidadores a avaliou como } \\
\text { "boa" a sua QV; O domínio } \\
\text { Meio Ambiente foi o } \\
\text { domínio mais afetado; foram } \\
\text { encontradas correlações } \\
\text { positivas estatisticamente } \\
\text { significantes entre o domínio } \\
\text { Meio Ambiente e as variáveis } \\
\text { sociodemográficas "nível } \\
\text { socioeconômico" e "grau de } \\
\text { instrução" }\end{array}$ \\
\hline $\begin{array}{l}\text { Barbosa; } \\
\text { Fernandes } \\
(2009)^{24}\end{array}$ & $\begin{array}{l}\text { Avaliar a qualidade de } \\
\text { vida dos cuidadores } \\
\text { de crianças incluídas } \\
\text { no espectro autístico } \\
\text { e determinar se há } \\
\text { algum tipo de relação } \\
\text { entre os diferentes } \\
\text { domínios e aspectos } \\
\text { demográficos de } \\
\text { escolaridade dos pais e } \\
\text { classe social }\end{array}$ & $\begin{array}{l}150 \\
\text { cuidadores }\end{array}$ & $\begin{array}{l}\text { Quantitativa/ } \\
\text { WHOQOL-Bref }\end{array}$ & $\begin{array}{l}\text { Saúde e sobrecarga } \\
\text { do cuidador do } \\
\text { TEA/ Não Há }\end{array}$ & $\begin{array}{l}\text { A análise estatística revelou } \\
\text { que não somente os aspectos } \\
\text { incluídos nos domínios físico, } \\
\text { psicológico e de relações } \\
\text { sociais do WHOQOL- } \\
\text { bref, mas questões sócio- } \\
\text { demográficas também } \\
\text { foram determinantes na } \\
\text { caracterização da QV dos } \\
\text { sujeitos; Fatores referentes } \\
\text { ao domínio Meio Ambiente, } \\
\text { como as dificuldades no } \\
\text { acesso aos serviços de saúde, } \\
\text { contribuem para o aumento } \\
\text { do nível de estresse dos } \\
\text { cuidadores de crianças e } \\
\text { adolescentes com TEA }\end{array}$ \\
\hline
\end{tabular}

Dentre os estudos selecionados, o ano com maior número de publicação de estudos foi 2016 $(n=4)$. Notou-se uma distribuição uniforme de publicações nos anos de 2008, 2010, 2011, 2014 e 2015 com uma publicação sobre o tema em cada ano, e nos anos de 2009, 2012, 2013, 2017 e 2018 com duas publicações em cada ano. Não foi encontrado nenhum estudo publicado no ano de 2007.

\section{Os sujeitos-alvo, o referencial teórico e os instrumentos utilizados nos estudos}

Dos 19 estudos selecionados para análise, oito foram realizados com familiares/cuidadores de crianças/ adolescentes com deficiência $^{11,12,16-18,23-25}$; três com cuidadores familiares de pessoas com deficiências com perfil misto (amostra composta por cuidadores de crianças/adolescentes, adultos e idosos) ${ }^{13,26,27}$; 06 não apresentaram informações sobre a idade do sujeito alvo de cuidado (apenas o tipo de deficiências destes) $10,15,20,21,22,28$; um estudo foi realizado com cuidadores familiares de idosos ${ }^{19} \mathrm{e} \mathrm{um}$ estudo com cuidadores de pessoas adultas com deficiências. ${ }^{14}$

A análise sobre o referencial teórico ou tema de aprofundamento teórico utilizado nas introduções e discussões mostrou que os grandes temas mais utilizados, isoladamente ou em conjuntos com outros temas, foram: Dados clínicos, sociodemográficos, impacto das deficiências na dinâmica familiar e/ou a família como protetora, provedora de cuidados e desenvolvimento $(42,10 \% / \mathrm{n}=08)^{12,14,18,20-22,25,26}$; Saúde e 
Quadro 2. Descrição dos principais dados encontrados nos artigos selecionados para a amostra final da revisão.

\begin{tabular}{|c|c|c|c|c|c|}
\hline Autores & Objetivo & $\begin{array}{c}\text { Participantes } \\
\text { do estudo }\end{array}$ & $\begin{array}{l}\text { Metodologia/ } \\
\text { instrumento } \\
\text { ou técnica para } \\
\text { avaliar QdVF }\end{array}$ & $\begin{array}{c}\text { Referencial Teórico } \\
\text { ou Tema de } \\
\text { aprofundamento } \\
\text { teórico/ Definição } \\
\text { de QV utilizada }\end{array}$ & Principais resultados \\
\hline $\begin{array}{l}\text { Vieira; } \\
\text { Fernandes } \\
(2013)^{25}\end{array}$ & $\begin{array}{l}\text { Avaliar a QV } \\
\text { autorreferida de } \\
\text { irmãos mais velhos } \\
\text { de crianças autistas } \\
\text { utilizando-se o } \\
\text { WHOQOL-abreviado }\end{array}$ & $\begin{array}{l}21 \text { irmãos } \\
\text { mais velhos. }\end{array}$ & $\begin{array}{l}\text { Quantitativa/ } \\
\text { WHOQOL- } \\
\text { Bref. }\end{array}$ & $\begin{array}{l}\text { Dinâmica e } \\
\text { dificuldades das } \\
\text { famílias de crianças } \\
\text { com TEA/ QV } \\
\text { segundo a OMS }\end{array}$ & $\begin{array}{l}\text { O domínio mais prejudicado } \\
\text { foi o meio ambiente; foi } \\
\text { possível perceber que tanto } \\
\text { os cuidadores de crianças } \\
\text { autistas quanto seus irmãos } \\
\text { percebem dificuldades em } \\
\text { sua QV, principalmente em } \\
\text { relação ao acesso aos serviços } \\
\text { de saúde e transporte, às } \\
\text { condições de moradia, à } \\
\text { segurança, ao lazer, aos } \\
\text { recursos financeiros, às } \\
\text { oportunidades de adquirir } \\
\text { informações e às habilidades; } \\
\text { os irmãos que responderam } \\
\text { ao questionário não relatam } \\
\text { uma QV significativamente } \\
\text { prejudicada }\end{array}$ \\
\hline $\begin{array}{l}\text { Moreira et } \\
\text { al. }(2016)^{26}\end{array}$ & $\begin{array}{l}\text { Analisar a percepção } \\
\text { de pais/cuidadores de } \\
\text { pessoas com Síndrome } \\
\text { de Down sobre } \\
\text { qualidade de vida }\end{array}$ & 10 cuidadores & $\begin{array}{l}\text { Qualitativa/ } \\
\text { entrevista } \\
\text { semiestruturada }\end{array}$ & $\begin{array}{l}\text { Dados Clínicos e } \\
\text { sociodemográficos } \\
\text { da SD/ QV segundo } \\
\text { a OMS }\end{array}$ & $\begin{array}{l}60 \% \text { dos entrevistados } \\
\text { participam de atividades } \\
\text { regulares de lazer, porém o } \\
\text { desejo por mais momentos de } \\
\text { lazer é presente e ao mesmo } \\
\text { tempo é fator limitante para } \\
\text { a QV dos pais/cuidadores; } \\
\text { evidencias de que a QV sofre } \\
\text { interferências pela ausência } \\
\text { de agravantes à saúde e a } \\
\text { mesma é influenciada pela } \\
\text { disponibilidade de serviços } \\
\text { de saúde; a QV na dimensão } \\
\text { família é vista pelos pais/ } \\
\text { cuidadores como uma } \\
\text { necessidade de estarem mais } \\
\text { próximos de seus filhos }\end{array}$ \\
\hline
\end{tabular}

continua

sobrecarga do cuidador $(21,05 \% / \mathrm{n}=4) ;^{15,19,24,28}$ e, Qualidade de vida relacionada à saúde $(21,05$ $\% / n=4)^{10,16,17,23}$. Apenas três artigos $(15,79 \%)$ exploraram diretamente o tema da qualidade de vida familiar incluindo aspectos relacionados ao construto (necessidades de apoio, bem-estar emocional, físico e material, interação familiar, dados demográficos e econômicos como preditores positivos ou negativos de qualidade de vida, política e serviços de apoio à família e a pessoa com deficiências, lazer e relações com a comunidade $)^{11,13,27}$.
Notou-se ainda que $68,4 \%(n=13)$ dos estudos utilizaram a definição de qualidade de vida adotada pela Organização Mundial da Saúde $(\mathrm{OMS})^{10,12,14-18,21-23,25,26,28} ; 21 \%$ dos artigos $(\mathrm{n}=04)$ não apresentaram nenhuma definição de qualidade de vida ${ }^{11,19,24,27}$ e que apenas $10,5 \%$, ou seja, dois artigos utilizaram a definição de qualidade de vida familiar ${ }^{13,20}$.

O WHOQOL-Bref foi o instrumento mais utilizado para avaliar a qualidade de vida ( $\mathrm{n}=$ 11) 12,14,15,18,19,21-25, seguido por entrevistas semiestruturadas $(n=5)^{13,16,17,26,27}$. Houve também um 
Quadro 2. Descrição dos principais dados encontrados nos artigos selecionados para a amostra final da revisão.

\begin{tabular}{|c|c|c|c|c|c|}
\hline Autores & Objetivo & $\begin{array}{c}\text { Participantes } \\
\text { do estudo }\end{array}$ & $\begin{array}{l}\text { Metodologia/ } \\
\text { instrumento } \\
\text { ou técnica para } \\
\text { avaliar QdVF }\end{array}$ & $\begin{array}{c}\text { Referencial Teórico } \\
\text { ou Tema de } \\
\text { aprofundamento } \\
\text { teórico/ Definição } \\
\text { de QV utilizada }\end{array}$ & Principais resultados \\
\hline $\begin{array}{l}\text { Rodrigues } \\
\text { et al., } 2018^{27}\end{array}$ & $\begin{array}{l}\text { Analisar o impacto } \\
\text { de deficiências } \\
\text { intelectuais severas } \\
\text { ou profundas nas } \\
\text { dimensões da FQoL } \\
\text { em uma amostra de } \\
\text { famílias brasileiras, } \\
\text { com o objetivo de } \\
\text { identificar uma } \\
\text { série de aspectos } \\
\text { que poderiam ser } \\
\text { modificados. }\end{array}$ & 15 mães & $\begin{array}{l}\text { Qualitativa/ } \\
\text { entrevista } \\
\text { semiestruturada. }\end{array}$ & $\begin{array}{l}\text { Qualidade de vida } \\
\text { familiar/ Dados } \\
\text { sociodemograficos } \\
\text { da população } \\
\text { brasileira/ não } \\
\text { apresenta um } \\
\text { conceito de } \\
\text { QdVF, mas usa o } \\
\text { Family Quality of } \\
\text { Life Survey 2006 } \\
\text { (FQOLS-2006) } \\
\text { como base e } \\
\text { referencia de QdVF. }\end{array}$ & $\begin{array}{l}\text { Impacto de aspectos } \\
\text { relacionados às questões de } \\
\text { administração de saúde no } \\
\text { QdVF como o SUS e seus } \\
\text { profissionais percebidos como } \\
\text { inadequados / percepções } \\
\text { das mães de que seus filhos } \\
\text { tinham menos acesso aos } \\
\text { serviços de saúde do que } \\
\text { eles acham necessário / } \\
\text { dificuldades na obtenção } \\
\text { de informações e acesso } \\
\text { aos serviços de saúde, bem } \\
\text { como a percepção de que a } \\
\text { qualidade do atendimento era } \\
\text { ruim/ redução das atividades } \\
\text { de lazer e recreação devido } \\
\text { à falta de serviços públicos } \\
\text { e transporte adequado/ } \\
\text { prejuízo na interação com a } \\
\text { comunidade devido à visão } \\
\text { das mães sobre o estigma } \\
\text { social relacionado ao filho } \\
\text { com deficiência }\end{array}$ \\
\hline $\begin{array}{l}\text { Kantorski et } \\
\text { al., } 2017^{28}\end{array}$ & $\begin{array}{l}\text { Identificar a } \\
\text { prevalência e os } \\
\text { fatores associados a } \\
\text { uma pior avaliação da } \\
\text { qualidade de vida dos } \\
\text { familiares de usuários } \\
\text { de CAPS na região Sul } \\
\text { do Brasil. }\end{array}$ & $\begin{array}{l}1.242 \\
\text { familiares de } \\
\text { usuários de } \\
\text { CAPS. }\end{array}$ & $\begin{array}{l}\text { Quantitativa/ } \\
\text { Questionário } \\
\text { elaborado pelos } \\
\text { pesquisadores. }\end{array}$ & $\begin{array}{l}\text { Saúde e sobrecarga } \\
\text { do cuidador e dados } \\
\text { sobre variáveis que } \\
\text { influenciam a QV/ } \\
\text { QV segundo a OMS. }\end{array}$ & $\begin{array}{l}\text { Os fatores encontrados } \\
\text { na pesquisa associados } \\
\text { a uma pior avaliação da } \\
\text { qualidade de vida foram: } \\
\text { escolaridade, facilidade de } \\
\text { acesso aos CAPS, eficácia } \\
\text { dos CAPS, apoio dos CAPS } \\
\text { na sobrecarga, divisão das } \\
\text { atividades do cuidado, } \\
\text { problema de saúde, relação } \\
\text { com a família e sentimento de } \\
\text { sobrecarga. }\end{array}$ \\
\hline
\end{tabular}

Fonte: Elaborado pelas autoras.

artigo que utilizou o Short-form Health Survey $(\mathrm{SF}-36)^{10}$, um artigo que fez uso questionário elaborado pelos próprios pesquisadores ${ }^{28}$, e um artigo que tratava do processo de adaptação e validação da escala Family Quality of Life Scale, ou Escala de Qualidade de Vida Familiar em português ${ }^{11}$.

\section{Qualidade de vida familiar ou qualidade de vida de familiares?}

Uma comparação entre os estudos sobre QdVF realizados em distintos países ${ }^{3,29,30}$ e que adotam referenciais teóricos e instrumentos de medidas específicos QdVF, com os estudos encontrados e selecionados na presente revisão de literatura, possibilita a observação de discrepân- 
cias entre os resultados obtidos nos dois cenários, confirmando a hipótese formulada para o presente estudo.

Tal comparação aponta para uma distinção entre o que se pode chamar de estudos sobre "qualidade de vida familiar" (de acordo com o que é proposto pela Teoria Unificada de QdVF) e estudos sobre "qualidade de vida de familiares" de pessoas com deficiência: o primeiro identifica e trabalha com variáveis que afetam o bem-estar e a qualidade de vida de toda família (tais como os fatores individuais de cada membro da família, os fatores de nível de suporte familiar e de nível de suporte individual e os fatores sistêmicos); e o segundo centra-se nas variáveis que interferem na qualidade de vida de apenas um dos membros da família, geralmente aquele que é afetado diretamente pelo impacto causado pela presença de uma pessoa que demanda cuidados especiais (tais como o impacto do cuidado e sobrecarga e presença de depressão na vida e saúde do cuidador - como pode ser observado na coluna resultados do Quadro 2).

Embora haja uma indissociação entre a qualidade de vida de cada membro da família com a qualidade de vida de toda família ${ }^{1}$, pois aquilo que afeta um membro da família exerce impacto em todos os outros membros ${ }^{31}$, há um contraste entre o que se entende por qualidade de vida de um familiar de pessoas com deficiências - portanto qualidade de vida individual - e QdVF. Diferentemente da qualidade de vida individual, que centra suas preocupações nas características pessoais e variáveis ambientais que exercem influência na qualidade de vida somente de um indivíduo, na QdVF pondera-se o bem-estar de todos os indivíduos que compõem a família, em termos do que é necessário para que todos, em conjunto, tenham uma boa vida ${ }^{1}$.

A partir de elementos como constructo de qualidade de vida, referencial teórico (ou tema de aprofundamento teórico), características dos instrumentos e dimensões de qualidade de vida encontrados nos estudos selecionados, apontamos algumas características que separam os dois tipos de estudo supracitados:

Com base na definição de qualidade de vida encontrada na maior parte dos artigos selecionados, é possível demarcar uma primeira distinção entre os dois tipos de estudos: A definição de qualidade de vida elaborada pela OMS refere-se a qualidade de vida como uma percepção do indivíduo de sua posição na vida no contexto da cultura e sistema de valores nos quais ele vive e em relação aos seus objetivos, expectativas, padrões e preocupações $^{32}$, definição esta que contrasta com o conceito de QdVF, que por sua vez trabalha a partir de uma visão coletiva, com ênfase no exame das percepções e dinâmicas da unidade familiar como um todo ${ }^{4}$ : uma percepção dinâmica de bem - estar da família, coletivamente e subjetivamente definidos e informados por seus membros, em que as necessidades de nível individual e familiar interagem $^{2}$.

As características dos instrumentos utilizados nos artigos selecionados e instrumentos próprios para aferição de QdVF demarcam outra diferença entre estudos de QdVF dos estudos de qualidade de vida de familiares, pois estes exercem influência direta no tipo de resultados encontrados pelos estudos de QdVF e estudos que tratam da qualidade de vida de um familiar.

Como citado anteriormente, os instrumentos padronizados e as técnicas utilizadas para avaliar a QdVF nos estudos selecionados foram o WHOQOL-Bref, o SF-36, a Escala de Qualidade de Vida Familiar e entrevistas (semiestruturadas ou estruturadas).

O WHOQOL-Bref contém 26 questões, distribuídas em quatro domínios ou dimensões (físico, psicológico, relações sociais e meio ambiente) $)^{32}$ e o SF-36 possui 36 questões divididas em oito dimensões (capacidade funcional, aspectos físicos, dor, estado geral de saúde, vitalidade, aspectos sociais, aspectos emocionais, saúde mental) e uma questão de avaliação comparativa entre as condições de saúde atual e a de um ano atrás ${ }^{33}$.

O WHOQOL-Bref e o SF-36 são instrumentos de medidas que avaliam a qualidade de vida a partir da percepção individual do respondente que, apesar de conter questões referentes ao ambiente e relações sociais, focam em medidas de desempenho ou estruturas físicas e psicológicas do sujeito em relação a esses contextos, possibilitam uma autoavaliação de aspectos objetivos e subjetivos de qualidade de vida, mas não permitem a expansão das respostas para a unidade familiar.

Os resultados encontrados nos estudos selecionados que utilizaram estas duas ferramentas para avaliar a QV apresentaram informações relacionadas à saúde do cuidador comprometida em quase todos os domínios avaliados pelo instrumento; da deficiências como desorganizadora da vida e do cotidiano do cuidador; da abdicação de atividades prazerosas, do isolamento social e redução das relações interpessoais para dedicação quase que exclusiva à tarefa do cuidado; do ambiente como fonte de estresse e das condições 
ligadas ao sujeito como fator de promoção ou de impedimento da percepção positiva ou negativa de QV. Em alguns estudos, os resultados obtidos apontam para uma QV positiva, embora sinalizem déficits em alguma área avaliada pelo instrumento (geralmente áreas psicológicas e ambientais).

Os referenciais teóricos ou temas de aprofundamento teórico centram-se no exame da relação existente entre a qualidade de vida, a saúde e a sobrecarga da tarefa do cuidado sob um prisma individual utilizando, de forma direta ou indireta, uma abordagem teórica de qualidade de vida mais voltada para aspectos psicológicos, os quais buscam em sua essência indicadores que tratam das reações subjetivas de um indivíduo às suas vivências, dependendo assim, primeiramente da experiência direta da pessoa cuja qualidade de vida está sendo avaliada e indica como os povos percebem suas próprias vidas, felicidade, satisfação, ${ }^{34}$ mas que pouco explora as variáveis da unidade familiar e do ambiente que estão interferindo diretamente na percepção insatisfatória de $\mathrm{QV}$, na identificação das necessidades de apoio do cuidador e nos apoios já existentes que poderiam incluir outros membros de forma efetiva na tarefa do cuidado, aliviar o estresse, melhorar as condições de saúde e retirar a sobrecarga do cuidador alvo do estudo.

Em contraste, como apontado anteriormente, as investigações sobre QdVF buscam entender a qualidade de vida de forma coletiva (grupo familiar), e nesse sentido diferentes autores têm focado suas pesquisas na conceituação, mensuração e aplicabilidade da Teoria Unificada de Qualidade de Vida Familiar. Os resultados desses estudos frequentemente buscam identificar as necessidades de apoios expressadas pelas famílias; entender a satisfação das famílias em relação aos apoios recebidos de fontes formais e informais; empreendem na compreensão de como a gravidade, tipo de deficiências e os dados demográficos e econômicos se constituem em preditores positivos ou negativos de qualidade de vida, ou como as crenças espirituais e a interação familiar positiva se constituem em aliadas na presença da sensação de bem-estar emocional ${ }^{1,3,29,30}$, entre outros determinantes.

No contexto da presente revisão de literatura, apenas três estudos conseguiram atingir dimensões presentes no conceito de QdVF, discutindo seus achados como variáveis que afetam toda família, são eles:

O estudo de Tomaz et al. ${ }^{13}$ que avaliou a QdFV de 15 famílias de pessoas com deficiências intelectuais moderadas, por meio de entre- vista semiestruturada e classificou seus achados em categorias a partir das nove dimensões de QdVF identificadas pelo grupo Quality of Life Research Unit. Os resultados encontrados apontaram desequilíbrio entre mães e pais na atenção e cuidado dispensados ao filho com deficiências; interferência na qualidade da relação conjugal; intensa simbiose entre mãe e filho com deficiências e interferência na relação com os demais filhos; dificuldades na obtenção de informações e no acesso a serviços de saúde e educação, somadas à percepção de qualidade insatisfatória dos cuidados prestados e a percepção destes serviços como grande fonte de estresse familiar; empobrecimento familiar e dificuldades financeiras como resultado do abandono do mercado de trabalho pelas mães e dificuldades em coordenar as agendas e os interesses dos diferentes membros da família como complicadores do lazer familiar.

O Estudo de Rodrigues et al. ${ }^{27}$ que avaliou a QdVF de 15 famílias de pessoas com deficiências intelectual severa, utilizando entrevista semiestruturada, classificando seus achados em categorias a partir da Family Quality of Life Survey 2006 (FQOLS-2006). Os resultados encontrados na pesquisa apontaram insatisfação com serviços públicos de saúde e com os profissionais atuantes neles; insatisfação com a quantidade e a qualidade dos atendimentos; dificuldades na obtenção de informações e acesso aos serviços de saúde; redução das atividades de lazer e recreação e prejuízo na interação com a comunidade.

E, por último, o estudo de Jorge et al. ${ }^{11}$, que foi realizado com instrumento quantitativo a partir do processo de validação da escala Beach Center Family Quality of Life Scale Beach para uso no Brasil. Os resultados apontam baixos índices de satisfação em domínios como bem-estar emocional, apoio relacionado à pessoa com deficiências, bem-estar físico e material e relação entre pais e filhos. Aponta ainda, alto nível de satisfação no domínio interação familiar.

Notou-se a partir dos resultados apresentados pelos estudos de Tomaz et al. ${ }^{13}$ e Rodrigues et al. ${ }^{27}$ que entrevista a semiestruturada configura-se numa excelente ferramenta de avaliação da QdVF em contextos com pouca disponibilidade ou ausência de instrumentos quantitativos próprios para este fim, como no caso brasileiro. A técnica apresenta ainda como vantagem a possibilidade de exploração do tema desejado com profundidade em estudos envolvendo pequenos grupos de sujeitos.

Cabe ressaltar que os primeiros estudos de avaliação da QdVF foram de natureza qualitativa 
por meio de grupos de discussão e entrevistas semiestruturadas. ${ }^{2}$ Esses estudos foram de extrema importância para o avanço da temática de QdVF, pois permitiram a construção de conceitos e de medidas quantitativas. Três instrumentos nasceram a partir dos resultados desses estudos, são eles $^{35}$ : a) O International Family Quality of Life Survey-2006 - FQoL-S-2006 que avalia a qualidade de vida em nove dimensões (bem-estar econômico, relações familiares, suporte de outras pessoas, apoios dos serviços que prestam cuidados à pessoa com deficiências, crenças culturais e espirituais, nível educacional e preparação para estudos, lazer e tempo livre, e envolvimento na comunidade) e já foi traduzida e adaptada para 12 idiomas e atualmente é utilizada em 18 países; b) A Beach Center Family Quality of Life Scale que avalia a qualidade de vida familiar em cinco dimensões (interação familiar, parentalidade, bem-estar emocional, bem-estar físico e material e apoio relacionado à deficiências) e já foi adaptada em países como China, Taiwan, Espanha, Colômbia, Brasil e Porto Rico; c) A Escala Latinoamericana de Calidad de Vida que possui 42 itens distribuídos em seis dimensões (bem-estar emocional, força e crescimento pessoal, normas de convivência, bem-estar físico e material, vida em família e relações sociais e com a comunidade) e tem por objetivo ser uma escala adequada ao contexto sociocultural e econômico da America Latina.

Todas essas escalas estão em consonância com a Teoria Unificada de Qualidade de Vida familiar, pois são centradas na família e buscam identificar variáveis que influenciam positivamente ou negativamente a QV de toda a unidade familiar.

Diante disso, vale ressaltar que a Teoria Unificada de $\mathrm{QdVF}^{2-4}$ tem sido a bússola de diversas investigações sobre QdVF em diferentes contextos culturais, e apesar de ser uma teoria nova, tem sido bem aceita entre os pesquisadores da área que têm se dedicado a investigar as dimensões de QdVF em cada uma das unidades da teoria (características familiares, características de cada membro da família, os apoios e as influências dos fatores sistêmicos na QdVF) ${ }^{30}$.

Enfatiza-se que a difusão da Teoria Unificada de QdVF e a adoção da mesma como referência poderia contribuir com o acesso aos instrumentos de pesquisa já desenvolvidos para este fim; com o desenvolvimento de instrumentos próprios para o contexto brasileiro, e para a consolidação da produção científica brasileira na tendência internacional dos estudos atuais sobre qualidade de vida de famílias de pessoas com deficiência.

\section{Considerações finais}

Qualidade de Vida Familiar é uma temática em plena expansão e crescimento que ganhou força nas últimas décadas nas pautas internacionais de pesquisas sobre pessoas com deficiência e suas famílias. Na contramão dessa realidade, os resultados da presente revisão de literatura apontam para uma produção científica nacional preocupada com o entendimento individual da qualidade de vida no que concerne às famílias de pessoas com deficiências.

Os resultados aqui encontrados também apontam para uma incipiência da temática na produção nacional com poucos estudos explorando o tema, com o uso expressivo de construtos individuais de qualidade de vida, e com a pouca presença de instrumentos de medidas que possibilitam a compreensão da qualidade de vida do grupo familiar.

Os poucos estudos encontrados, além de explorarem a qualidade de vida das famílias apontam as necessidades de apoios formais e informais que as famílias com membros com deficiências possuem, e que se constituem como barreiras para o alcance do bem-estar familiar. 


\section{Colaboradores}

AC Nunes contribuiu com a concepção, delineamento metodológico, busca, análise e interpretação dos dados, e redação do artigo. EAM Luiz contribuiu com a concepção, delineamento metodológico, busca e redação do artigo. PCSD Barba contribuiu com a concepção, delineamento metodológico, redação do artigo e aprovação da versão final a ser publicada.

\section{Referências}

1. Poston D, Turnbull A, Park J, Mannan H, Marquis J, Wang M. Family quality of life: A qualitative inquiry. Ment Retard 2003; 41(5):313-328.

2. Zuna NI, Turnbull A, Summers JA. Family quality of life: Moving from measurement to application. J Policy Pract Intellect Disabil 2009; 6(1):25-31.

3. Chiu C, Kyza K, Zuna N, Turnbull A, Summers J A, Aya-Gomez V. Family quality of life. In: Wehmeyer ML, editor. The Oxford handbook of positive psychology and disability. Oxford: Oxford University Press; 2013; 365-392.

4. Zuna N I, Summers JA, Turnbull AP, Hu X, Xu S. Theorizing About Family Quality of Life. In: Kober R, editor. Enhancing the Quality of Life of People with Intellectual Disability: From theory to practice. Dordrecht: Springer; 2010. p. 241-278.

5. Verdugo MA, Rodriguez A, Sainz F. Escala de calidad de vida familiar Manual de aplicación. Salamanca: Publicaciones del INICO; 2012.

6. Brown I, Brown RI. Concepts for beginning study in family quality of life. In: Turnbull A, Brown I, Turnbull R, editores. Families and people with mental retardation and quality of life: International perspectives. Washington, DC: American Association on Mental Retardation; 2004. p. 25-49.

7. Turnbull AP, Summers JA, Lee SH, Kyzar K. Conceptualization and measurement of family outcomes associated with families of individuals with intellectual disabilities. Ment Retardation Dev Disabil Res Rev 2007; 13(4):346-356.

8. Brasil. Lei no 13.146, de 6 de julho de 2015. Dispõe sobre a Lei Brasileira de Inclusão da Pessoa com Deficiência [Internet]. 2015 [acessado 2019 jan 9]. Disponível em: http://www.planalto.gov.br/ccivil_03/_Ato20152018/2015/Lei/L13146.htm

9. Mendes KDS, Silveira RCCP, Galvão CM. Revisão integrativa: método de pesquisa para a incorporação de evidências na saúde e na enfermagem. Texto Contexto 2008; 17(4):758-764.

10. Costa TF, Gomes TM, Viana LRC, Martins KP, Costa KNFM. Acidente vascular encefálico: características do paciente e qualidade de vida de cuidadores. Rev Bras Enferm 2016; 69(5):933-939.

11. Jorge BM, Levy CCAC, Granato L. Adaptação Cultural da Escala de Qualidade de Vida Familiar (Family Quality of Life Scale) para o Português Brasileiro. CoDAS; 27(6):534-540.

12. Nascimento GB, Schiling NO, Ubal SR, Biaggio EPV, Kessler TM. Classificação socioeconômica e qualidade de vida de familiares de crianças e adolescentes com deficiência auditiva. Rev CEFAC 2016; 18(3):657666.

13. Tomaz RVV, Santos VA, Silva ALR, Germano C MR, Melo DG. Impacto da deficiência intelectual moderada na dinâmica e na qualidade de vida familiar: um estudo clínico-qualitativo. Cad Saude Publica 2017; 33(11):e00096016.

14. Ponte AS, Fedosse E. Lesão Encefálica Adquirida: impacto na atividade laboral de sujeitos em idade produtiva e de seus familiares. Cien Saude Coletiva 2016; 21(10):3171-3182.

15. Braccialli LMP, Bagagi PDS, Sankako AN, Araújo RDCT. Qualidade de vida de cuidadores de pessoas com deficiência. Rev Bras Educ Espec 2012; 18(1):113126. 
16. Oliveira MFS, Silva MBM, Frota MA, Pinto JMS, Frota LMCP, Sá FP. Qualidade de vida do cuidador de crianças com paralisia cerebral. Rev Bras Promoc Saude 2008; 21(4):275-280.

17. Oliveira MFS, Silva MBM, Frota MA, Pinto JMS, Frota LMCP, Sá FP. Qualidade de vida do cuidador de crianças com paralisia cerebral. Rev Bras Promoc Saude 2008; 21(4):275-280.

18. Fávero-Nunes MA, Santos MA. Depressão e qualidade de vida em mães de crianças com transtornos invasivos do desenvolvimento. Rev Latino-Am Enfermagem 2010; 18(1):33-40.

19. Reis LA, Santos KT, Reis L A, Gomes NP. Quality of life and associated factors for caregivers of functionally impaired elderly people. Braz J Phys Ther 2013; 17(2):146-151.

20. Silva RS, Fedosse E. Perfil sociodemográfico e qualidade de vida de cuidadores de pessoas com deficiência intelectual. Cad Bras Ter Ocup 2018; 26(2):357-366.

21. Bittencourt ZZLC, Hoehne EL. Qualidade de vida de familiares de pessoas surdas atendidas em um centro de reabilitação. Cien Saude Colet 2009; 14(4):12351239.

22. Lima ML, Santos JLF, Sawada NO, Lima LAP. Qualidade de vida de indivíduos com acidente vascular encefálico e de seus cuidadores de um município do Triângulo Mineiro. Rev Bras Epidemiol 2014; 17(2):453-464.

23. Oliveira EF, Limongi SCO. Qualidade de vida de pais/ cuidadores de crianças e adolescentes com síndrome de Down. J Soc Bras Fonoaudiol 2011; 23(4):321-327.

24. Barbosa MRP, Fernandes FDM. Qualidade de vida dos cuidadores de crianças com transtorno do espectro autístico. Rev Soc Bras Fonoaudiol 2009; 14(4): 482-486.

25. Vieira CBM, Fernandes FDM. Qualidade de vida em irmãos de crianças incluídas no espectro do autismo. CoDAS 2013; 25(2): 120-127.

26. Moreira RM, Oliveira BG, Cruz DP, Bomfim E S, Camargo CL, Sales ZN. Qualidade de vida de cuidadores familiares de pessoas com Síndrome de Down. Rev Pesqui Cuid Fundam 2016; 8(3):4826-4832.

27. Rodrigues SA, Fontanella BJB, Avó LRS, Germano CMR, Melo DG. A qualitative study about quality of life in Brazilian families with children who have severe or profound intellectual disability. J Appl Res Intellect Disabil 2018; 32:413-426.

28. Kantorski LP, Jardim VMR, Treichel CAS, Mola CL, Alves PF, Ferreira RZ, Oliveira MM. Fatores associados a uma pior avaliação da qualidade de vida entre familiares cuidadores de usuários de Centros de Atenção Psicossocial. Cad Saude Colet 2017;
25(4):460-467.

29. Hu X, Wang M, Fei X. Family quality of life of Chinese families of children with intellectual disabilities. J Intellect Disabil Res 2012; 56(1):30-44.

30. Mas JM, Baqués N, Balcells-Balcells A, Dalmau M, Giné C, Gràcia M, Vilaseca R. Family quality of life for families in early intervention in Spain. J Early Interv. 2016; 38(1): 59-74.

31. McWilliam RA, editor. Routines-based early intervention - Supporting Young Children and Their Families. New York/ London; The Guilford Press; 2010.

32. Fleck MPA, Louzada S, Xavier M, Chachamovich E, Vieira G, Santos L, Pinzon V. Aplicação da versão em português do instrumento abreviado de avaliação da qualidade de vida "WHOQOL-bref". Rev Saude Publica 2000; 34(2):178-183.

33. Ciconelli RM. Tradução para o português e validação do questionário genérico de avaliação de qualidade de vida Medical Outcomes Study 36-Item Short-Form Health Survey (SF-36) [tese]. São Paulo: Universidade Federal de São Paulo; 1997.

34. Pereira EF, Teixeira CS, Santos A. Qualidade de vida: abordagens, conceitos e avaliação. Rev Bras Educ Fis Esporte 2012; 26(2):241-250.

35. Giné C, Momplet RV, García MG, Rueda CS, Montalá MD, Beltran FS, Balcells AB, Hernández MTP, Pinatella DS, Alcocer ALA, Valdés AGY, Del Gredorio VC, Mas JM. Las escalas de calidad de vida familiar (cdvf-e): apoyo y orientación para la intervención. Siglo Cero: Revista Española sobre Discapacidad Intelectual; 44(247):21-36.

Artigo apresentado em 02/07/2018

Aprovado em 27/08/2019

Versão final apresentada em 29/08/2019

Editores-chefes: Romeu Gomes, Antônio Augusto Moura da Silva 